\section{To compare serum Vitamin D status in pre-eclamptic and non-preeclamptic pregnant women in labour: A tertiary care centre study of Northern India}

\author{
Monica Karpa ${ }^{1}$, Sita Thakur ${ }^{2}$, Kamal Singh ${ }^{3 *}$, Jyoti Sharma ${ }^{1}$ \\ and Harsha Chaudhary ${ }^{1}$
}

1 Junior Resident, OBG, Dr. Rajendra Prasad Government Medical College, Kangra, HP, India ${ }^{2}$ Professor, Dr. Rajendra Prasad Government Medical College, Kangra, HP, India ${ }^{3}$ Lecturer, Dr. Rajendra Prasad Government Medical College, Kangra, HP, India

\section{Abstract}

Background: Pre-eclampsia and eclampsia have remained a major global public health threat in contributing significantly to maternal and perinatal morbidity and mortality. Based on the inverse relationship between serum $1,25(\mathrm{OH}) 2 \mathrm{D} 3$ levels and plasma renin activity found previously, it is speculated that $1,25(\mathrm{OH}) 2 \mathrm{D} 3$ might be a negative endocrine regulator of renin production in vivo. During pregnancy, vitamin $D$ may play a role in implantation and placental function potentially due to angiogenic, immunomodulatory, and antiinflammatory effects. Vitamin D deficiency can affect the health of both mother and fetus by increasing the production of inflammatory cytokines and stimulating the activity of T-regulating cells. Vitamin D is emerging as a promising agent for pre-eclampsia prevention.

Aims and objectives: The objective of this study is to compare the vitamin D levels in preeclamptic and healthy non-pre-eclamptic pregnant women in labor and find out the relationship between vitamin $D$ levels and pre-eclampsia.

Methodology: The present cross-sectional study was carried out on pregnant women with pre-eclampsia in labor. For each case with pre-eclampsia, one uncomplicated, normotensive pregnant woman in labor was taken as control. On admission to the labor room detailed history, physical examination followed by thorough obstetrics and systemic examination was done. Required investigations were done including vitamin $D$ and calcium levels. Maternal and fetal condition was monitored during labor/cesarean section, mode of delivery, maternal and fetal outcomes were recorded. After delivery, 2cc of cord blood was collected in a serum tube and sent for vitamin D levels. Data was collected and analyzed statistically using Epi-info version 7.1.

Results: It was observed that the patients in both groups were comparable with respect to demographic and obstetrics characteristics except for significantly high BP in group I. Vitamin D deficiency (i.e. $<20 \mathrm{ng} / \mathrm{ml}$ ) was significantly more in group I as compared to group II and the difference was highly significant $(p<0.0001)$. Similarly, the mean maternal calcium levels were significantly lower in group I in comparison to group II $(p<0.0001)$ i.e. the mean maternal calcium level in group I and group II were $8.03 \pm 0.94$ and $9.19 \pm 0.67$ respectively. It was also observed that the level of 25-OH-D in neonates of preeclamptic women was significantly lower than for those of the normal pregnant women $(p<0.0001)$.

Conclusion: Vitamin D deficiency is highly prevalent in all parts of the world. Pregnant women and neonates are highly vulnerable to vitamin D deficiency. Preeclampsia is indeed associated with lower vitamin $\mathrm{D}$ levels and the pathophysiology of pre-eclampsia involves vitamin $\mathrm{D}$ and calcium metabolism through their role in immunomodulation, angiogenesis and anti-inflammatory effects. From the present study, it was observed that vitamin D and calcium levels were significantly lowered in women with pre-eclampsia as compared to those of the normotensive pregnant women. So early detection of vitamin $D$ and calcium deficiencies may be helpful in preventing occurrence of PET and its complications.
More Information

*Address for Correspondence: Dr. Kamal Singh, MD (OBG), Set no. 28 block E type IV, Dr. Rajendra Prasad Government Medical College, Kangra, HP, India 176001, Email: singh.kamal396@gmail.com

Submitted: January 07, 2022

Approved: January 27, 2022 Published: January 28, 2022

How to cite this article: Karpa M, Thakur S, Singh K, Sharma J, Chaudhary H. To compare serum Vitamin D status in pre-eclamptic and non-preeclamptic pregnant women in labour: A tertiary care centre study of Northern India. Clin J Obstet Gynecol. 2022; 5: 013-018.

\section{DOI: 10.29328/journal.cjog.1001100}

Copyright License: ( 2022 Karpa M, et al. This is an open access article distributed under the Creative Commons Attribution License, which permits unrestricted use, distribution, and reproduction in any medium, provided the original work is properly cited.

Keywords: Pre-eclampsia; Normotensive; Vitamin D; Calcium metabolism; Immunomodulatory; Angiogenesis

(D) Check for updates

OPEN ACCESS 


\section{Introduction}

Pre-eclampsia (PE) is a pregnancy-specific syndrome, affecting many bodily systems, characterized by high blood pressure which develops after 20 weeks of gestation, complicating $2 \%$ - $8 \%$ of pregnancies and increasing maternal and fetal mortality and morbidity [1]. Pre-eclampsia and eclampsia have remained a major global public health threat in contributing significantly to maternal and perinatal morbidity and mortality [2]. According to a study in 2014, the global incidence of pre-eclampsia and eclampsia was $2.16 \%$ and $0.28 \%$, respectively. Corresponding figures in India are $1.97 \%$ and $0.43 \%$, respectively [3]. Pre-eclampsia can lead to eclampsia, which can put the mother and her fetus at risk of death [5].

During pregnancy, vitamin D may play a role in implantation and placental function potentially due to angiogenic, immunomodulatory, and antiinflammatory effects [2]. Vitamin D deficiency is highly prevalent in women of reproductive age and in pregnant mothers. Vitamin D deficiency can affect the health of both mother and fetus by increasing the production of inflammatory cytokines and stimulating the activity of T-regulating cells. It results in poor bone mineralization in infants, low birth weight, and other adverse pregnancy outcomes [8].

The rennin-angiotensin system (RAS) is a regulatory cascade that plays an essential role in the regulation of blood pressure, electrolyte and volume homeostasis. Inappropriate stimulation of the RAS has been associated with hypertension [4]. Animal and human studies suggest that vitamin D deficiency may increase activity of the rennin-angiotensin system. Individuals with low 25(OH)D levels have increased systemic and kidney specific RAS activation, whereas hypertensive individuals with polymorphisms in the vitamin D receptor also have increased RAS activation [4-7].

The role of vitamin $\mathrm{D}$ in pre-eclampsia is related to the effect of vitamin D on renin-angiotensin system (RAS). Vitamin $D$ is a negative endocrine regulator of RAS, which suppresses renin gene expression. Therefore, serum vitamin $D$ levels are inversely associated with blood pressure and renin activity [22]. Pre-eclampsia is thought to originate in early pregnancy when the maternal immune system limits placental invasion in mothers vulnerable to cardiovascular diseases. Calcitriol can be considered a pregnancy supporting factor that could work through several mechanisms to reduce pre-eclampsia risk including a direct influence of calcitriol on implantation, placental invasion and angiogenesis.

Vitamin D is emerging as a promising agent for preeclampsia prevention. Several studies have demonstrated an association between higher 25-hydroxy vitamin D $(25[\mathrm{OH}] \mathrm{D})$ levels in pregnancy and reduced risk of preeclampsia, especially severe preeclampsia $[4,8]$. Compared to normal pregnancies, vitamin D metabolism is markedly altered in preeclampsia. This may be due to reduced placental 1-alfa hydroxylase activity resulting in lower circulating calcitriol concentrations compared to normotensive or chronically hypertensive pregnant women [20].

US Endocrine Society has defined vitamin D levels as follows:

Deficiency $<20 \mathrm{ng} / \mathrm{ml}(50 \mathrm{nmol} / \mathrm{L})$

Insufficiency $21-29 \mathrm{ng} / \mathrm{ml}(52.5-72.5 \mathrm{nmol} / \mathrm{L})$

Sufficiency $>30 \mathrm{ng} / \mathrm{ml}(65 \mathrm{nmol} / \mathrm{L})$

Toxicity $>150 \mathrm{ng} / \mathrm{ml}$

$(\mathrm{ng} / \mathrm{ml} \times 2.5=\mathrm{nmol} / \mathrm{l})$

To our knowledge, there is no published data in the population of Himachal Pradesh, northern India regarding vitamin D levels in preeclamptic and healthy normotensive pregnant women. The objective of this study is to determine vitamin D status, based on the serum 25(OH)D concentrations in pregnant women with pre-eclampsia and compare it with that of healthy pregnant controls.

\section{Aims and objectives}

The objective of this study is to compare the vitamin D levels in pre-eclamptic and healthy non-pre-eclamptic pregnant women in labor and find out the relationship between vitamin D levels and pre-eclampsia.

\section{Material and methods}

The present cross-sectional study was carried out in the Department of Obstetrics and Gynaecology, Dr. Rajendra Prasad Government Medical College, Kangra at Tanda, (H.P.) on pregnant women with pre-eclampsia in labor after the approval from the institutional ethical committee and protocol review committee. For each case with pre-eclampsia, one uncomplicated, normotensive pregnant woman in labor was taken as control. Both the groups were matched for demographic data (age, parity, period of gestation, BMI).

International Society for the study of Hypertension in Pregnancy (ISSHP) defines pre-eclampsia as: BP $>/ 140 / 90$ $\mathrm{mmHg}$ after 20 weeks of gestation and the existence of one or more of the following conditions: proteinuria $>/ 1+$ dipstick, other maternal organ dysfunction: (renal, liver neurological and hematological complications) and uteroplacental dysfunction during pregnancy [5]. They were grouped into two groups, group I (100 women presenting with preeclampsia with systolic BP of $140 \mathrm{mmHg}$ or higher, and or diastolic BP of $90 \mathrm{mmHg}$ or higher on two occasions 4 hours apart with proteinuria ) and group II (100 healthy normotensive pregnant women with comparable demographic characteristics).

Inclusion criteria: A singleton pregnancy with preeclampsia in labor, Healthy normotensive singleton pregnant women as control. 
Exclusion criteria: History of chronic medical disorder (pre-existing diabetes mellitus, chronic hypertension), intestinal malabsorption, any evidence of liver, kidney, or gastrointestinal diseases. The use of medications that affect serum vitamin D level e.g. anticonvulsants, antituberculosis drugs.

On admission to the labor room, detailed history including obstetric history, menstrual history, POG, past history, medical history, surgical history, history of allergy to drugs was taken followed by thorough examination. General physical examination of the patient as per protocol was carried out followed by a thorough systemic examination to rule out any systemic disease. Detailed obstetric examination including abdominal, per speculum and per vaginum examination was done and the required investigations were done. Blood sample was taken in a serum test tube and sent for vitamin D and calcium levels along with other investigations.

Antihypertensive and seizure prophylaxis if required were given as per the institutional protocols. After stabilization, the patients were planned for the mode of termination of pregnancy which was decided as per indication. i.e induction/ augmentation of labour/cesarean section.

Maternal and fetal conditions were monitored during labor/cesarean section, mode of delivery (vaginal/cesarean section), maternal and fetal outcome were recorded. After delivery, 2cc of cord blood sample was taken in a sterile tube and sent for vitamin D levels. Patient was monitored in the postpartum or post-operative period as per institutional protocol. The samples were sent to the biochemistry laboratory. Quantification of serum 25(OH)D was performed using a commercial enzyme-linked immunosorbent assay.

\section{Statistical analysis}

Results obtained were analyzed statistically using Epi-info version 7.1 and Microsoft Excel.

\section{Observations}

The participants were divided into two groups, group I (100 women presenting with preeclampsia in labor) group II (100 healthy normotensive pregnant women with comparable demographic characteristics) and the study was conducted w.e.f January 2018 to January 2019. Following observations were made:

Table 1 shows the mean age of group I and group II was $26.79 \pm 4.35$ years and $26.04 \pm 3.05$ years respectively. Majority of the patients (41\%) were in the age-group of 2125 years group followed by 26-30 years (39\%). More than $90 \%$ of women in both groups were booked $(97 \%$ in group I and $94 \%$ in group II). As this institute mainly caters to the rural population. So, the majority of patients in the two groups belonged to rural area i.e. $88 \%$ in group I and $86 \%$ in group II. It was observed that $82 \%$ of women in group I and $64 \%$ of

\begin{tabular}{|c|c|c|c|}
\hline Table 1: Baseline demographic and obstetrics characteristics. N = 200. & $\begin{array}{c}\text { Group I } \\
\text { (pre eclamptic) } \\
\mathbf{N}=100\end{array}$ & $\begin{array}{c}\text { Group II } \\
\text { (healthynormotensive) } \\
\mathbf{N}=100\end{array}$ & $p$ value \\
\hline Mean age & $26.79 \pm 4.35$ years & $26.04 \pm 3.05$ years & 1.000 \\
\hline BMI & $22.69 \pm 3.08$ & $22.31 \pm 2.96$ & 0.32 \\
\hline $\begin{array}{c}\text { Booking status \% of } \\
\text { booked/unbooked }\end{array}$ & $97 / 3$ & $94 / 6$ & 0.495 \\
\hline $\begin{array}{c}\text { Residential \% of } \\
\text { Rural/urban }\end{array}$ & $88 / 12$ & $86 / 14$ & 0.833 \\
\hline $\begin{array}{c}\text { Mean POG } \\
\text { Mean systolic } \\
\text { BP mmHg }\end{array}$ & $37.80 \pm 2.17$ weeks & $38.06 \pm 1.89$ weeks & 0.309 \\
\hline $\begin{array}{c}\text { Mean diastolic BP } \\
\text { mmHg }\end{array}$ & $162.30 \pm 12.34$ & $115.40 \pm 5.46$ & $<0.0001$ \\
\hline
\end{tabular}

women in group II belonged to the lower middle class. Only $3 \%$ of patients in each in the group were below the poverty line. The difference regarding socioeconomic status was statistically significant $(p=0.011)$.

Regarding the education status of patients, majority of patients i.e. $45 \%$ in group I and $60 \%$ in group II were educated upto $12^{\text {th }}$ standard. None of the women in both groups was illiterate. In group I, $4 \%$ of patients and in group II, $7 \%$ patients were underweight $(\mathrm{BMI}<18.5)$ and $16 \%$ in group I, and $10 \%$ in group II were overweight (BMI 25-29.9). BMI distribution was comparable between 2 groups $(p=0.32)$.

In group I, $65 \%$ of patients and in group II, $69 \%$ of patients were with zero parity. None of the patients in both the groups was para 5 or above. Majority of the women were full-term with period of gestation $\geq 37$ weeks ( $73 \%$ in each group) and $27 \%$ of women in each group had premature gestation. In group I, $6 \%$ and in group II, only $2 \%$ of women had a period of gestation between 31 weeks to 31 weeks 6 days. The difference was not statistically significant ( $p=0.309$ ).

The mean systolic blood pressure in group I and in group II was $162.30 \pm 12.34$ and $115.40 \pm 5.46$ respectively and the mean diastolic blood pressure in group I and group II was $102.52 \pm 8.51$ and $71.18 \pm 4.41$ respectively We observed that mean systolic as well diastolic blood pressure at the time to admission was significantly higher in group I in comparison to group II $(p<0.0001)$

In the present study, none of the women in group I had normal vitamin D levels (i.e. > $30 \mathrm{ng} / \mathrm{ml}$ ) whereas, $27 \%$ of women in the control group had normal vitamin D levels and the difference was highly significant $(p=0.0001)$. The mean vitamin D level in group I and in group II were $8.87 \pm 4.66$ (vitamin D deficient) and $25.83 \pm 7.07$ (vitamin D insufficient) respectively and were significantly lower in group I in comparison to group II $(p<0.0001)$. Vitamin D deficiency (i.e. $<20 \mathrm{ng} / \mathrm{ml}$ ) was significantly more in group I as compared to group II ( $p<0.0001)$ as out of 100 women in the group I, 97 women had vitamin D deficiency whereas in group II only 25 out of 100 women had vitamin D deficiency. It was observed that in pregnant women with pre-eclampsia, vitamin D levels were significantly lower as compared to healthy normotensive pregnant women. 
The mean maternal calcium level in group I and group II was $8.03 \pm 0.94 \mathrm{mg} / \mathrm{dl}$ and $9.19 \pm 0.67 \mathrm{mg} / \mathrm{dl}$ respectively. We observed that mean maternal calcium levels were significantly lower in group I in comparison to group II $(p=0.0001)$ (Table 2).

Induction of labor was done in $53 \%$ of patients of group I, whereas only $10 \%$ of women in group II had induction of labour. As shown in Figure 1, significantly more number of women in the control group (i.e.89\%) had normal vaginal delivery as compared to the women in the study group (i.e.48\%). In contrast, the incidence of operative delivery was much higher in the study group as compared to the control group, i.e. $52 \%$ and $11 \%$ respectively. None of the patients had operative vaginal delivery in group II while 3 patients in group I had an operative vaginal delivery.

In the present study, 86 out of 100 women in group II and only one-third (i.e. 32 women) in group I had birth weight $>$ $2.5 \mathrm{~kg}$. In the pre-eclamptic group, 61 out of 100 newborns had birth weight between $1.5-2.5 \mathrm{~kg}$ whereas only 12 newborns in the control group had birth weight between $1.5-2.5 \mathrm{~kg}$. There was no neonatal mortality in the present study. In group I, $7 \%$ of neonates had birth weight $<1.5 \mathrm{~kg}$ whereas only $2 \%$ of neonates in group II were low birth weight. In group I, 20\% of neonates were admitted to NICU for more than 24 hours whereas in group II only $2 \%$ of neonates had NICU admission.

\begin{tabular}{|c|c|c|c|c|c|}
\hline \multirow[b]{2}{*}{ Vitamin D levels (ng/ml) } & \multicolumn{2}{|c|}{$\begin{array}{c}\text { Group I } \\
\text { (pre eclamptic) } \\
\text { N = } 100\end{array}$} & \multicolumn{2}{|c|}{$\begin{array}{c}\text { Group II } \\
\text { (healthy normotensive) } \\
\mathrm{N}=100\end{array}$} & \multirow[t]{2}{*}{$p$ value } \\
\hline & No. of cases & $\%$ & No. of cases & $\%$ & \\
\hline$<=20$ & 97 & 97 & 25 & 25 & \multirow{4}{*}{0.0001} \\
\hline $21-30$ & 3 & 3 & 48 & 48 & \\
\hline$>30$ & 0 & 0 & 27 & 27 & \\
\hline Mean & \multicolumn{2}{|c|}{$8.87 \pm 4.66$} & \multicolumn{2}{|c|}{$25.83 \pm 7.07$} & \\
\hline \multicolumn{6}{|l|}{ Calcium levels (mg/dl) } \\
\hline$<8.5$ & 70 & 70 & 12 & 12 & \multirow{4}{*}{$<0.0001$} \\
\hline $8.5-11.0$ & 29 & 29 & 88 & 88 & \\
\hline$>11.0$ & 1 & 1 & 0 & 0 & \\
\hline Mean \pm SD & \multicolumn{2}{|c|}{$8.03 \pm 0.94$} & \multicolumn{2}{|c|}{$9.19 \pm 0.67$} & \\
\hline
\end{tabular}

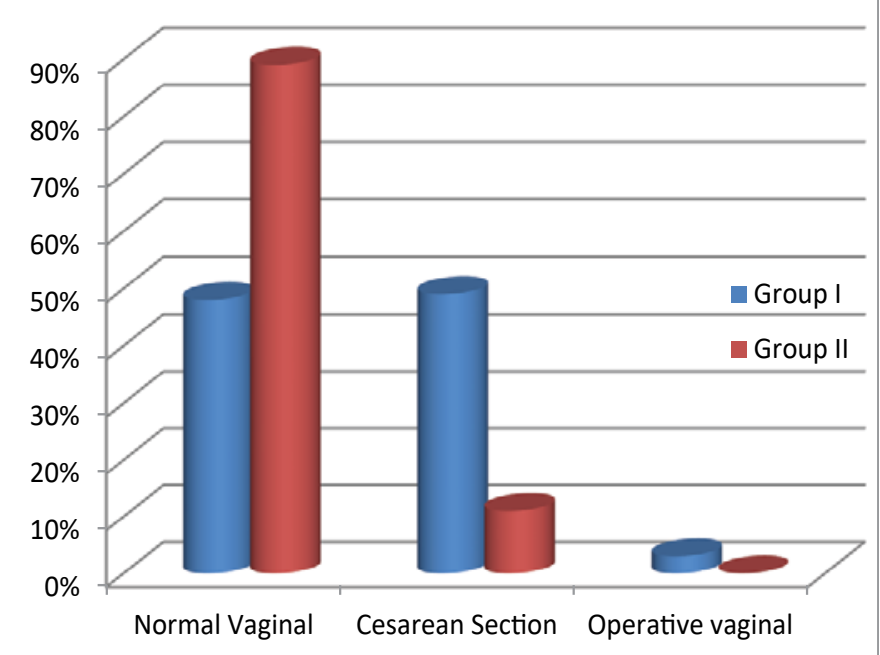

Table 3 shows the cord blood vitamin D levels in both groups.

The mean cord blood vitamin D level of group I and group II was $6.99 \pm 2.45$ (vitamin D deficient) and $21.93 \pm 5.53$ (vitamin D insufficient) respectively.

The mean level of 25-OH-D in neonates of preeclamptic women was significantly lower than for those of the normal pregnant women $(6.99 \pm 2.45$ vs. $21.93 \pm 5.53 \mathrm{ng} / \mathrm{ml}$, $p=0.0001$ ). The number of neonates with vitamin D deficiency in preeclamptic women was higher than that in the normal pregnant group ( $p=0.0001)$. Only six neonates in group II had sufficient vitamin D level (> $30 \mathrm{mg} / \mathrm{ml}$ ) and none in group I.

\section{Discussion}

Vitamin D deficiency is a worldwide epidemic, with a prevalence that ranges from $18 \%$ to $84 \%$ depending on the country of residence, ethnicity, and local clothing customs and dietary intake. Clinical studies establishing an association between vitamin D levels and adverse pregnancy outcomes such as preeclampsia, gestational diabetes, and low birth weight, preterm labor, and cesarean delivery have conflicting results [21].

Preeclampsia is a multisystem disorder defined as newonset hypertension and proteinuria. There is a growing interest in the role of maternal vitamin D status in the development of preeclampsia.

Vitamin D deficiency is highly prevalent in women of reproductive age and in pregnant mothers. The mean age of patients in our study and in various other studies to compare maternal vitamin D levels in pre-eclamptic and normotensive women was in the range of 22-30 years. In the present study, the mean age of patients in group I and in group II was comparable to the studies done by Abedi, et al. [13] and Mohaghegh, et al. [15].

In the present study majority of patients in the two groups were having normal BMI ( $80 \%$ in group I and $83 \%$ in group II) similar to studies by Abedi, et al. [13] and Mohaghegh, et al. [15]. suggesting no significant relationship between BMI and PET as most of the patients had BMI within the normal range in both groups (Table 4).

In the present study the mean POG in group I was $37.80 \pm$

\begin{tabular}{|c|c|c|c|c|c|}
\hline \multirow[t]{2}{*}{$\begin{array}{l}\text { Cord blood vitamin D } \\
\text { levels (ng/ml) }\end{array}$} & \multicolumn{2}{|c|}{$\begin{array}{c}\text { Group I } \\
\text { (pre eclamptic) } \\
\mathrm{N}=100\end{array}$} & \multicolumn{2}{|c|}{$\begin{array}{c}\text { Group II } \\
\text { (healthy normotensive) } \\
\mathrm{N}=100\end{array}$} & \multirow[t]{2}{*}{$p$ value } \\
\hline & No. of cases & $\%$ & No. of cases & $\%$ & \\
\hline$<20$ & 100 & 100 & 42 & 42 & \multirow{4}{*}{0.0001} \\
\hline $21-30$ & 0 & 0 & 52 & 52 & \\
\hline$>30$ & 0 & 0 & 6 & 6 & \\
\hline Mean & \multicolumn{2}{|c|}{$6.99 \pm 2.45$} & \multicolumn{2}{|c|}{$21.93 \pm 5.53$} & \\
\hline
\end{tabular}


Table 4: Demographic and obstetrical characterstics of various studies.

\begin{tabular}{|c|c|c|c|c|c|c|c|c|c|c|}
\hline \multirow[b]{2}{*}{ Groups } & \multicolumn{2}{|c|}{ Abedi, et al. [13] } & \multicolumn{2}{|c|}{ Mohaghegh, et al. [15] } & \multicolumn{2}{|c|}{ Bakacak, et al. [14] } & \multicolumn{2}{|c|}{ Gogaram, et al. [19] } & \multicolumn{2}{|c|}{ Present study } \\
\hline & I & II & I & II & I & II & 1 & II & I & II \\
\hline AGE & $26.58 \pm 5.3$ & $23.31 \pm 4.04$ & $26.4 \pm 5.6$ & $24 \pm 4.4$ & $28.9 \pm 5.80$ & $29.2 \pm 8.40$ & $23.42 \pm 3.36$ & $23.28 \pm 3.58$ & $26.79 \pm 4.35$ & $26.04 \pm 3.05$ \\
\hline BMI & $22.39 \pm 3.6$ & $23.6 \pm 3.5$ & $23.3 \pm 3.9$ & $23.4 \pm 3.1$ & $29.3 \pm 4.75$ & $30.6 \pm 3.72$ & & & $22.69 \pm 3.08$ & $22.31 \pm 2.96$ \\
\hline POG & $37.5 \pm 0.66$ & $38.8 \pm 1.23$ & $37.5 \pm 0.6$ & $39.3 \pm 1.2$ & $35.3 \pm 2.94$ & $38.5 \pm 1.43$ & $35.3 \pm 2.94$ & $38.5 \pm 1.43$ & $37.80 \pm 2.17$ & $38.06 \pm 1.89$ \\
\hline SBP & $148 \pm 10.5$ & $109 \pm 7.5$ & $148.2 \pm 10.4$ & $107 \pm 7.5$ & 156 & 114.5 & & & $162.30 \pm 12.34$ & $115.40 \pm 5.46$ \\
\hline DBP & $93.9 \pm 7.8$ & $69.07 \pm 8.1$ & $94.6 \pm 8.6$ & $107 \pm 7.5$ & $105.7 \pm 6.62$ & $68.9 \pm 8.77$ & & & $102.52 \pm 8.51$ & $71.18 \pm 4.41$ \\
\hline
\end{tabular}

2.17 weeks and in group II it was $38.06 \pm 1.89$ weeks which was comparable to the study done by Abedi, et al. [13] and Mohaghegh, et al. [15]. However, in the study by Bakacak, et al. [14] and Gogaram, et al. [19] the mean gestational age of women in preeclamptic group was significantly lower than the control group.

The mean systolic and mean diastolic BP of patients in our study was $162.30 \pm 12.34 \mathrm{mmHg}$ and $102.52 \pm 8.51 \mathrm{mmHg}$ in the preeclamptic group and $115.40 \pm 5.46 \mathrm{mmHg}$ and $71.18 \pm$ $4.41 \mathrm{mmHg}$ in the normotensive group, similar observations were made in the study by Bakacak, et al. [14]. However the mean systolic and diastolic BP at admission was lower than the present study in the study by Abedi, et al. [13] and Mohaghegh, et al. [15].

Table 5 shows the maternal vitamin D levels in various studies. The mean vitamin D levels in the study group was $8.87 \pm 4.66 \mathrm{ng} / \mathrm{ml}$ (vitamin D deficiency) and in the control group was $25.83 \pm 7.07 \mathrm{ng} / \mathrm{ml}$ (vitamin D insufficiency) and the difference was highly significant and is comparable to studies by Mohaghegh, et al. [15] and Bakacak, et al. [14].

Whereas in the study conducted by Dhillon, et al. [18], Sadin, et al. [11], Sahu, et al. [17] and Mehmood, et al. [16] there was a universal prevalence of vitamin D deficiency among the pregnant females, but the level of serum vitamin $\mathrm{D}$ was significantly lower in the preeclamptic group as compared to the normotensive. The above findings in different studies may indirectly suggest that vitamin D deficiency could increase the risk of pre-eclampsia.

In the present study, the mean maternal serum calcium levels in the preeclamptic women were $8.03 \pm 0.94 \mathrm{mg} / \mathrm{dl}$ and in the normotensive women was $9.19 \pm 0.67 \mathrm{mg} / \mathrm{dl}$ ( $p=<0.001$ ) similarly to the studies done by Sahu, et al. [17] and Gupta, et al. [10] the mean serum calcium level in group I was below $8.5 \mathrm{mg} / \mathrm{dl}(8.30 \pm 1.46 ; 8.50 \pm 0.80)$ and in group II was above $8.5 \mathrm{mg} / \mathrm{dl}(8.82 \pm 0.92 ; 8.89 \pm 0.55)$.

\begin{tabular}{|c|c|c|c|}
\hline \multicolumn{2}{|c|}{ Table 5: Mean maternal vitamin d levels. } \\
\hline \multirow{2}{*}{ Authors } & \multicolumn{2}{|c|}{ Mean maternal vitamin D(ng/ml) } & \multirow{2}{*}{ p value } \\
\hline Mohaghegh, et al.[15] & $15.26 \pm 13.6$ & $23.3 \pm 15.3$ & 0.001 \\
\hline Bakacak, et al. [14] & $19.3 \pm 4.31$ & $23.7 \pm 5.93$ & $<0.001$ \\
\hline Dhillon, et al. [18] & $9.83 \pm 6.11$ & $14.92 \pm 3.35$ & 0.04 \\
\hline Sadin, et al. [11] & $10.09 \pm 6.60$ & $15.73 \pm 5.85$ & 0.002 \\
\hline Sahu, et al. [17] & $9.06 \pm 5.20$ & $13.67 \pm 7.24$ & $<0.001$ \\
\hline Mehmood, et al. [16] & $6.78 \pm 3.55$ & $9.43 \pm 4.86$ & 0.002 \\
\hline Present study & $8.87 \pm 4.66$ & $25.83 \pm 7.07$ & $<0.001$ \\
\hline
\end{tabular}

In our study, the number of neonates with vitamin $\mathrm{D}$ deficiency $(<20 \mathrm{ng} / \mathrm{ml})$ in the preeclamptic group was higher than that in the normotensive group (100\% vs. $42 \%)$ which is comparable to the study by Mohaghegh, et al. [15] suggesting that direct link between maternal vitamin D level in PET with low level in neonates. Whereas in a study by Gupta, et al. [10] although the neonates of both the groups had vitamin D deficiency with vitamin D levels of $4.40 \mathrm{ng} / \mathrm{ml}$ and $7.25 \mathrm{ng} /$ $\mathrm{ml}$ in group I and group II respectively but significantly low in group I as compared to group II.

\section{Conclusion}

From the present study, it was observed that vitamin D and calcium levels were significantly lowered in women with pre-eclampsia as compared to those of the non-pre-eclampsia pregnant women. Early detection of deficiencies of these parameters may be helpful in preventing the occurrence of PET and its complications. So, this study has raised the possibility of the association of maternal vitamin D deficiency with that of PET. There is an extreme lack of awareness regarding the importance of vitamin D and its sources, especially in the population of Himachal Pradesh. Women of childbearing age should be well supplemented by taking diets rich in vitamin D so as to prevent vitamin D deficiency and insufficiency later in pregnancy. This might reduce the risk of developing preeclampsia and also prevent neonatal vitamin D deficiency.

\section{References}

1. Steegers EA, von Dadelszen P, Duvekot JJ, Pijnenborg R. Preeclampsia. Lancet. 2010; 376: 631-644.

PubMed: https://pubmed.ncbi.nlm.nih.gov/20598363/

2. Nagaria T, Mitra S, Banjare SP. Single loading Low Dose MgSO4 Regimen: A simple, safe and effective alternative to Pritchard"s Regimen for Indian Women. J Clin Diagnos Res. 2017; 11: QC06-12. PubMed: https://pubmed.ncbi.nlm.nih.gov/28969211/

3. Abalos E, Cuesta C, Carroli G, Qureshi Z, Widmer M, et al. WHO Multicountry Survey on Maternal and Newborn Health Research Network. Preeclampsia, eclampsia and adverse maternal and perinatal outcomes: a secondary analysis of the World Health Organization Multicountry Survey on Maternal and Newborn Health. BJOG. 2014; 121: 14-24.

PubMed: https://pubmed.ncbi.nlm.nih.gov/24641531/

4. Magee LA, Dadelszen PV, Stones W. The FIGO Textbook of Pregnancy Hypertension; London: The Global Library of Women"s Medicine. 2016; 1

5. Say L, Chou D, Gemmill A, Tuncalp O, Moller AB, et al. Global causes of maternal death: a WHO systematic analysis. Lancet Glob Health. 2014; 2: 323-333.

PubMed: https://pubmed.ncbi.nlm.nih.gov/25103301/ 
6. Chun LY, Guilin Q, Milan U, Wei X, Wei Z, et al. Vitamin D: a negative endocrine regulator of the renin-angiotensin system and blood pressure. J Steroid Biochem Mol Biol. 2004; 89-90: 387-392. PubMed: https://pubmed.ncbi.nlm.nih.gov/15225806/

7. Duley L. The global impact of preeclampsia and eclampsia. Semin Perinatol. 2009; 33: 130-137.

PubMed: https://pubmed.ncbi.nlm.nih.gov/19464502/

8. Regmi MC, Aggrawal A, Pradhan T. Loading dose versus standard regimen of magnesium sulphate in eclampsia-a randomized trial Nepal Med Coll J. 2010; 12: 244-247.

PubMed: https://pubmed.ncbi.nlm.nih.gov/21744767/

9. Gordon R, Magee LA, Payne B, Firoz T, Sawchuck D, et al. Magnesium Sulphate for the management of preeclampsia and eclampsia in low and middle income countries: a systematic review of tested dosing regimens. J Obstet Gynaecol Can. 2014; 36: 154-163.

PubMed: https://pubmed.ncbi.nlm.nih.gov/24518915/

10. Taru G, Sonika W, Nupur G, Sarika A, Sangeeta G, et al. Correlation of Vitamin D Levels in Term Normotensive and Pre-eclamptic Patients in Labor. J Obstetr Gynecol India. 2016; 66: 154-159.

PubMed: https://pubmed.ncbi.nlm.nih.gov/27298523/

11. Sadin B, Gargari BP, Tabrizi FPF. Vitamin D Status in Preeclamptic and Non-preeclamptic Pregnant Women: A Case-Control Study in the North West of Iran. Health Promot Perspect. 2015; 5: 183-190. PubMed: https://pubmed.ncbi.nlm.nih.gov/26634196/

12. Baker AM, Haeri S, Camargo CA Jr, Espinola JA, Stuebe AM. A nested case-control study of midgestation vitamin $D$ deficiency and risk of severe preeclampsia. J Clin Endocrinol Metab 2010; 95: 5105-5109. PubMed: https://pubmed.ncbi.nlm.nih.gov/20719829/

13. Abedi P, Mohaghegh Z, Afshary P, Latifi M. The relationship of serum vitamin $\mathrm{D}$ with pre-eclampsia in the Iranian women. Matern Child Nutr. 2014; 10: 206-212.

PubMed: https://pubmed.ncbi.nlm.nih.gov/23782626/

14. Bakacak M, Serin S, Ercan O, Köstü B, Avci F, et al. Comparison of Vitamin D levels in cases with preeclampsia, eclampsia and healthy pregnant women. Int J Clin Exp Med. 2015; 8: 16280-16286. PubMed: https://pubmed.ncbi.nlm.nih.gov/26629145/

15. Mohaghegh Z, Abedi P, Dilgouni T, Namvar F, Ruzafza S. The relation of preeclampsia and serum level of 25-hydroxyvitamin $D$ in mothers and their neonates: a case control study in Iran. Horm Metab Res. 2015; 47: 284-288.

PubMed: https://pubmed.ncbi.nlm.nih.gov/25611206/

16. Mehmood S, Karim SA. Vitamin D Deficiency during Pregnancy and its Relationship with Pre-Eclampsia, Eclampsia and Gestational Hypertension. Austin J Nutr Metab. 2016; 3: 1040.

17. Sahu M, Das V, Agarwal A, Rawat V, Saxena P, et al. Vitamin D replacement in pregnant women in rural north india: a pilot study. Eur $\mathrm{J}$ Clin Nutr. 2009; 63: 1157-1159.

PubMed: https://pubmed.ncbi.nlm.nih.gov/19455177/

18. Dhillon MK, Bedi GK, Kaur K. Significance of 25 hydroxy vitamin D and calcium in pregnancy induced hypertension. Int J Health Sci Res. 2017; 7: 80-85.

19. Gogaram, Prasad H, Misha S. Comparison of maternal serum vitamin d levels in cases with preeclampsia, eclampsia and healthy pregnant women in Churu District. IJBAMR. 2018; 7: 282-288.

20. Fischer D, Schroer A, Ludders D, Cordes T, Bücker B, et al. Metabolism of vitamin D3 in the placental tissue of normal and preeclampsia complicated pregnancies and premature births. Clin Exp Obstet Gynecol. 2007; 34: 80-84.

PubMed: https://pubmed.ncbi.nlm.nih.gov/17629157/

21. Behjat Sasan S, Zandvakili F, Soufizadeh N, Baybordi E. The Effects of Vitamin D Supplement on Prevention of Recurrence of Preeclampsia in Pregnant Women with a History of Preeclampsia. Obstet Gynecol Int. 2017; 8249264

PubMed: https://pubmed.ncbi.nlm.nih.gov/28912817/

22. Li YC, Kong J, Wei M, Chen ZF, Liu SQ, et al. 1,25-Dihydroxyvitamin $D 3$ is a negative endocrine regulator of the renin-angiotensin system. $J$ Clin In-vest. 2002; 110: 229-238.

PubMed: https://pubmed.ncbi.nIm.nih.gov/12122115/ 